\title{
Urgência subjetiva na Psicanálise e Enfermagem: revisão integrativa
}

\author{
Letícia Rodrigues Barbosa* \\ Jeferson Rodrigues** \\ Maico Fernando Costa*** \\ Vitor Augusto Werner dos Reis****
}

\section{Resumo}

Objetivo: neste estudo, buscou-se descrever as características das produções científicas relativas à urgência subjetiva e identificar as produções científicas que relacionem urgência subjetiva, psicanálise e enfermagem. Método: Para isso, foi realizada uma revisão integrativa de literatura nas bases de dados: LILACS, SCIELO, (MEDLINE) PUBMED, CINAHL PSYCINFO, PEPSIC, Web of Science, SCOPUS, BDENF e BVS. O recorte temporal foi de 2010 a 2020 , sendo incluídos artigos nos idiomas português, inglês e espanhol. Resultados: Foram selecionados 14 artigos, por meio dos quais constatou-se que a maioria das publicações ocorreram na região sudeste e que os profissionais que mais produziram sobre o tema foram psicólogos com formação em psicanálise. Evidenciou-se também a ausência da produção e da publicação sobre urgência subjetiva por enfermeiros independente da formação em psicanálise. Cumpre destacar que a urgência subjetiva é um tema abordado no campo da Psicanálise sob os referenciais de Freud e Lacan. Salienta-se ainda que O estudo teve como categoria a Experiência do Sujeito, o Reconhecimento e a Intervenção da urgência subjetiva. Conclusão: conclui-se que a urgência subjetiva na esfera da produção científica da enfermagem mostra-se ainda frágil, podendo também refletir que, no âmbito da atuação desse profissional, a urgência subjetiva é ausente como referência clínica.

Palavras-chave: Urgência subjetiva, Psicanálise, Enfermagem.

\section{Subjective urgency in Psychoanalysis and Nursing: integrative review}

\begin{abstract}
Objective: To describe the characteristics of scientific productions related to subjective urgency, and to identify scientific productions that relate subjective urgency, psychoanalysis, and nursing. Method: An integrative literature review was conducted in the following databases: LILACS, SCIELO, (MEDLINE) PUBMED, CINAHL PSYCINFO, PEPSIC, Web of Science, SCOPUS, BDENF and BVS. The time frame was from 2010 to 2020. Articles in Portuguese, English and Spanish were included. Results: Fourteen articles were selected. It was found that most of the publications were from the southeast region, the professionals who produced the most on the theme were psychologists and those with training in psychoanalysis. It was evidenced that the production and publication on subjective urgency by nurses, regardless of their training in psychoanalysis, is absent. Subjective urgency is a theme addressed in the field of Psychoanalysis under the references of Freud and Lacan. The study had as a category the Subjective Urgency Experience, Recognition and Intervention. Conclusion: We conclude that subjective urgency in the sphere of nursing scientific production is still fragile, which may also reflect that subjective urgency is absent as a clinical reference within the scope of nursing practice.
\end{abstract}

Key Words: Subjective urgency, Psychoanalysis, Nursing.

* Universidade Federal de Santa Catarina. Acadêmica do Curso de Graduação em Enfermagem da Universidade Federal de Santa Catarina. leticiarodriguesbarbosa2203@gmail.com .

** Universidade Federal de Santa Catarina. Professor Associado I do Departamento de Enfermagem da Universidade Federal de Santa Catarina. jef_rod@hotmail.com .

*** Universidade Estadual Paulista. Psicólogo e psicanalista. Doutorando pela Universidade Estadual Paulista. maicofernandodd@gmail.com .

**** Universidade do Sul de Santa Catarina. Psicólogo e psicanalista. Doutorando em Ciências da Linguagem da Universidade do Sul de Santa Catarina. vitorwerner@gmail.com . 


\section{Introdução}

$\mathrm{Na}$ prática da enfermagem, assim como em outras profissões da área da saúde, trabalha-se principalmente com a percepção do "corpo" na esteira do modelo biomédico. Embora a assistência seja baseada em perspectivas do cuidado integral, as intervenções que aludem à subjetividade remontam ao jargão "queixa conduta".

A psicanálise é um dos campos de conhecimento que se ocupa da subjetividade, por meio das formações do inconsciente. Segundo Freud (1922[1996], p. 253) a psicanálise é "um procedimento para a investigação de processos mentais que são quase inacessíveis por qualquer outro método". Para a psicanálise, o sujeito é constituído da relação da pessoa com o mundo, a partir dos relacionamentos que a psicanálise denomina de "grande Outro", o qual dá ao sujeito o significado da sua existência. Assim, o sujeito se torna o produto do laço cultural do meio onde está inserido e da história da sua vida (Sbardelotto et al.,2016). Segundo Kaszubowski (2018, p. 118), o "sujeito deve recorrer ao outro para se fazer conhecer e se reconhecer".

À vista disso, sabe-se que as relações humanas e as experiências de vida podem causar sofrimento e angústia que deixam marcas traumatizantes no sujeito. Um sofrimento que, por vezes, não é compreendido pelo sujeito no instante em que acontece, podendo incidir na ruptura do real, por isso, esse momento é vivido com desespero. Esse tempo é estudado na psicanálise como urgência subjetiva, no instante em que o sujeito pode nomear esse fenômeno, reconhecendo-se nas cenas de sua história e articulando a queixa com outras questões suas.

Na prática comum, a urgência é tratada como uma situação médica em que o organismo sofre uma quebra na sua funcionalidade fisiológica, e o tempo é a peça fundamental, considerando a gravidade da circunstância em que a vida está sob ameaça, a qual se classifica como uma condição crítica cuja conduta requer atendimento de forma rápida, visto que o risco de vida é iminente (Sotelo, 2020).

Quando se fala de urgência na esfera da psiquiatria, da saúde mental e da atenção psicossocial, refere-se à condição em que a desordem de pensamento, emoção, afeto ou comportamento está em um estágio tão alterado que demanda cuidado imediato ao paciente, sendo considerada uma urgência que advém do campo da subjetividade, o qual vai além daquilo que podemos observar no corpo físico do paciente (Sotelo, 2020).
Segundo Barros (2008, p.53), a palavra "urgência tem origem no verbo latino urgere, que significa empurrar ou compelir". Para o psicanalista identificar e apontar o que diz respeito sobre o que pulsiona o sujeito, é o que tange à característica de urgência para a psicanálise (Barros, 2008, p.53).

Sob a ótica da subjetividade, a urgência é o momento em que a pessoa experimenta um desassossego, um momento inesperado de desespero, causando uma ruptura momentânea do psiquismo e das identificações. Segundo Costa (2019, p.146), "a inoperância do circuito simbólico é a consequência da quebra das identificações"; o sujeito não consegue localizar a capacidade de assimilar o que ocorreu naquele instante, tampouco se reconhece um meio para começar a expressar os seus sentimentos. Para o sujeito, o momento da urgência subjetiva acontece de maneira tão repentina que faltam as palavras para sustentar o discurso (Costa, 2019). Para o sujeito, a urgência subjetiva representa a interrupção com o real, com aquilo que representa a sua história até aquele exato momento (Calazans \& Bastos, 2008). Em outras palavras, o sujeito vivencia os efeitos do encontro com o real, porém, dessa vez, já recorrendo a sentidos para dar conta daquilo que o atravessa, como uma angústia. A urgência subjetiva já é a subjetividade trabalhando frente à realidade que foi apresentada. Desse modo, a abordagem sobre a urgência subjetiva tem por objetivo permitir ao sujeito compreender o fator que ocasionou a crise, criando um cenário que possibilite um enfrentamento ao sofrimento, por meio do questionamento sobre si próprio, uma intervenção que acontece por intermédio da palavra, ou seja, há um entendimento de que o sofrimento psíquico diz respeito ao sujeito, mas que ele também não sabe localizá-lo, por isso a importância da escuta (Calazans \& Bastos 2008).

Diante do exposto sobre essa realidade de sujeitos que se encontram em um momento de crise - o que para a psicanálise se caracteriza por urgência subjetiva, na qual esse sujeito necessita de ajuda para retornar a si próprio -, torna-se significativa a presente pesquisa por descrever as características das produções científicas em relação à urgência subjetiva no sentido de reforçar a importância da ampliação do olhar da enfermagem no que tange às urgências que seguem o padrão clínico. Além disso, sua importância se dá por observar, quase que exclusivamente, o corpo físico, norteando esse profissional a identificar urgências que não estão expostas no corpo. 
Desse modo, formulou-se a seguinte pergunta de pesquisa: Quais são as características das produções científicas relativas à urgência subjetiva na psicanálise e na enfermagem? Sendo assim, este artigo tem como objetivo descrever as características das produções científicas relativas à urgência subjetiva e identificar as produções científicas que relacionem urgência subjetiva, psicanálise e enfermagem.

\section{Método}

Este estudo trata-se de uma revisão integrativa com abordagem qualitativa, a qual seguiu os passos proposto por (Ganong, 1987): seleção da questão de pesquisa; estabelecimento de critérios para inclusão e exclusão de estudos e seleção da amostra; representação dos estudos selecionados em formato de tabelas, considerando as características em comum; análise crítica dos resultados, identificação de diferenças e conflitos; discussão e interpretação dos resultados; apresentação das evidências de forma clara.

Foi produzido um protocolo de pesquisa que passou pela validação de duas professoras doutoras em enfermagem com expertise em Método de Revisão e em Conteúdo, com a finalidade de manter o rigor científico e metodológico acerca da definição do método de investigação, extração dos dados dos artigos selecionados, análise e apresentação dos resultados.

A pergunta norteadora da pesquisa foi: Quais são as características das produções científicas relativas à urgência subjetiva na psicanálise e na enfermagem? As buscas foram realizadas nos meses de junho a agosto de 2020. Os artigos foram selecionados de acordo com os seguintes critérios de inclusão: artigos na íntegra, nos idiomas português, inglês e espanhol e publicados nos bancos de dados nos últimos dez anos (2010 a 2020). Foram excluídos textos duplicados e textos que não correspondiam ao escopo da pesquisa.

A seleção dos artigos ocorreu em quatro etapas, sendo elas: 1) a execução da estratégia de busca nas bases de dados, com a colaboração do profissional bibliotecário, por meio dos descritores cadastrados nos Descritores em Ciências da Saúde (Decs) e no Medical Subject Headings (Mesh): Urgência subjetiva, Subjective Urgency, emergencia subjetiva, Urgencia subjetiva, Intervenção na Crise, Intervenções na crise, Crisis Intervention, Crisis Interventions, Intervención en la Crisis, Interrogatório em
Incidente Crítico com Estresse, Critical Incident Stress Debriefing, Disminución del Estrés del Incidente Crítico, Psicanálise, Psychoanalysis, Psicoanálisis; 2)execução dos filtros; 3) leitura do título e resumo com exclusão dos artigos que não apresentaram a temática da pesquisa; e 4) leitura dos textos na íntegra para seleção final dos artigos, para composição da revisão integrativa realizada pela pesquisadora.

Destaca-se que descritores relacionados à Enfermagem, como: enfermagem e saúde mental foram excluídos, justificando que as suas inclusões levaram a resultados nulos.

Para a seleção dos artigos, foram utilizadas as seguintes bases de dados: Literatura da America Latina e Caribe (LILACS), Scientific Electronic Library Online (SCIELO), Medical Literature OnLine (MEDLINE) PUBMED, Cumulative Index to Nursing and Allied Health Literature (CINAHL) American Psychological Association (PSYCINFO), Periódicos Eletrônicos de Psicologia (PePSIC), BDENF (Enfermagem; américa latinas, SCOPUS (Multidisciplinar; abrangência mundial), Web of Science (Multidisciplinar; abrangência mundial) e Biblioteca Virtual em Saúde (BVS).

Os artigos selecionados foram lidos na íntegra e organizados em uma planilha com as seguintes informações: título, ano de publicação, referência completa, autores, formação dos autores, local onde o estudo foi realizado, tipo de estudo, objetivos, principais resultados. (Veja figura 1).

O método realizado para a análise dos artigos foi a análise temática de Minayo (2014). Esse método contempla três etapas: 1) pré-análise; 2) exploração do material; e 3) codificação e tratamento dos resultados obtidos, que permitem o material ser explorado por meio da busca de palavras que contenham significados de acordo com o objetivo da pesquisa.

\section{Resultados}

Os resultados apresentados seguiram a estratificação de dados nos estudos e contemplaram uma descrição do ano do estudo; local onde a pesquisa foi realizada; objetivos apresentados nos estudos; formação dos autores; métodos e tipo de estudo; e conceitos de urgência subjetiva. A seguir, apresentam-se as referências completas dos estudos desta pesquisa: 
Figura 1 - Prisma (Fluxograma) da coleta de dados e seleção dos estudos que compõem a amostra.

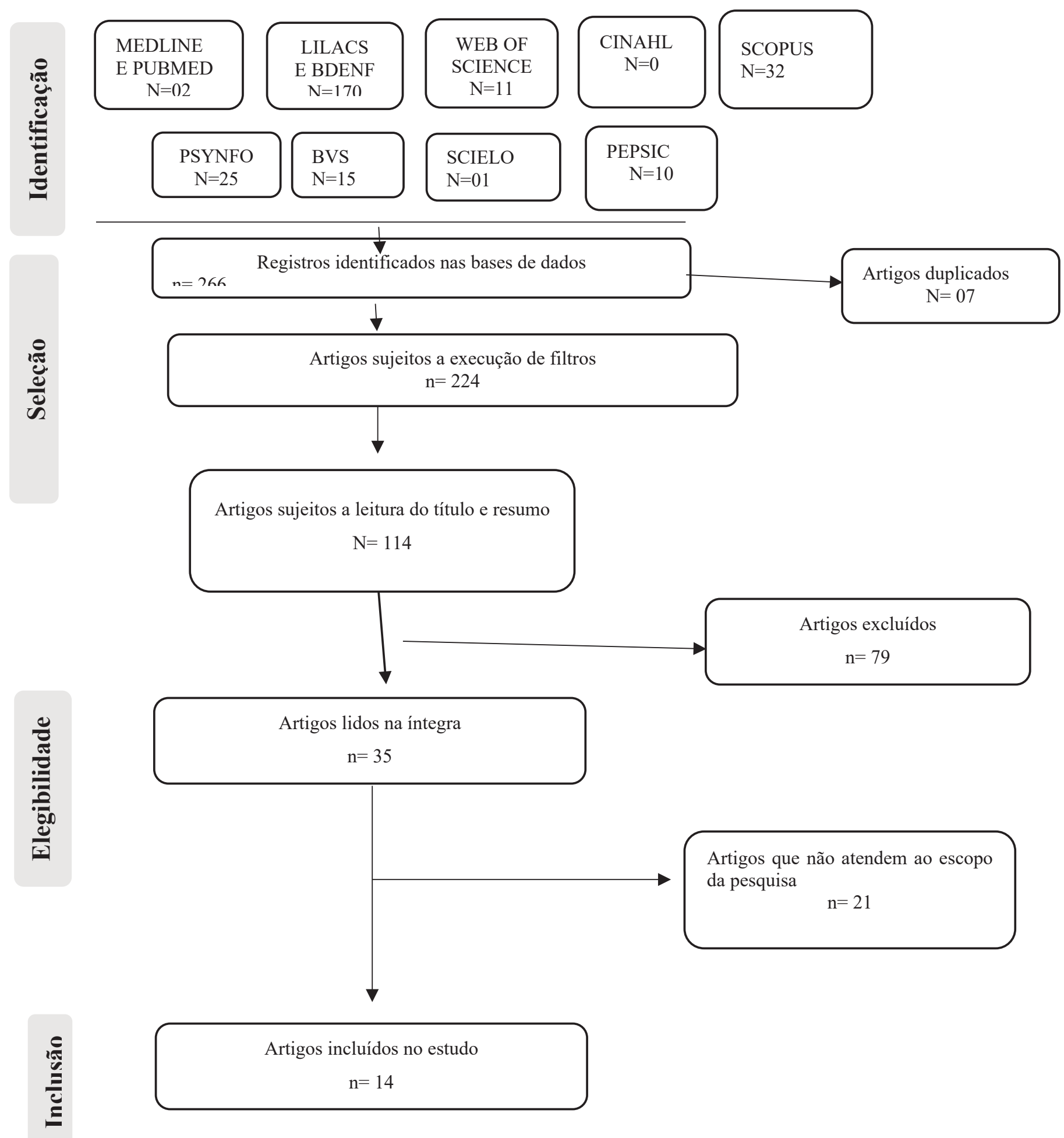


Quadro 1 - Artigos incorporados à revisão integrativa

\begin{tabular}{|c|c|}
\hline $\begin{array}{l}\text { Identificação } \\
\text { Artigo }\end{array}$ & Referência Completa \\
\hline A 2 & $\begin{array}{l}\text { Rodrigues, J. A., Dassoler, V. A., \& Cherer, E. Q. (2012). A aplicabilidade do dispositivo clínico- } \\
\text {-institucional urgência subjetiva no tratamento da toxicomania. Mental, 18(10), 69-88. }\end{array}$ \\
\hline A 3 & $\begin{array}{l}\text { Macêdo, L. F.; Pimenta Filho, J. A., Sotelo, M. I., Belaga, G., \& Santimaría, L. (2010). Análisis de } \\
\text { la demanda e intervenciones en la urgencia en salud mental. Psicologia em Revista, 116), 1-16. }\end{array}$ \\
\hline A 4 & $\begin{array}{l}\text { Ferrari, I. F. (2010). Centro de Acolhimento da Crise: Hospital Galba Velloso e algumas de suas } \\
\text { respostas aos desafios da reforma psiquiátrica. Psicologia em Revista, 3(16), 517-536. }\end{array}$ \\
\hline A 6 & $\begin{array}{l}\text { Costa, M. F., \& Costa-Rosa, A. (2018). O dispositivo clínica da urgência na atenção hospitalar: } \\
\text { sofrimento, escuta e sujeito. Revista Subjetividades, 18(2), 45-58. }\end{array}$ \\
\hline A 7 & $\begin{array}{l}\text { Santos, J. L. G., \& Costa-Moura, F. (2012). Precipitação da angústia na estruturação do sujeito } \\
\text { pelo significante. Arquivos Brasileiros de Psicologia, 64(2), P. 64-75. }\end{array}$ \\
\hline A 8 & $\begin{array}{l}\text { Costa, M. F.; Costa-Rosa, A., \& Amaral, C. H. A. (2016). Uma psicologia precavida pela psicaná- } \\
\text { lise: a clínica da urgência na unidade de pronto-socorro. Revista de Psicologia da Unesp, 15(2), 36-50. }\end{array}$ \\
\hline A 11 & $\begin{array}{l}\text { Muñoz, N. M., Vilanova, A., Tenembaum, D., \& Velasco, L. B. (2019). O manejo da urgência } \\
\text { subjetiva na universidade: construindo estratégias de cuidado à saúde mental dos estudantes. } \\
\text { Interação em Psicologia, 23(2), 177-183. http://dx.doi.org/10.5380/psi.v23i02.58547 }\end{array}$ \\
\hline A 12 & $\begin{array}{l}\text { Marcos, C., \& D’alessandro, C. (2013). Figuras psíquicas do trauma: uma leitura lacaniana. Revista } \\
\text { Asephallus, 8(15),35-38. }\end{array}$ \\
\hline A 13 & $\begin{array}{l}\text { Rodrigues, P. M. (2012). Práticas psicanalíticas de regulação em urgências subjetivas no hospital. } \\
\text { Revista Asephallus, 7(14),97-105. }\end{array}$ \\
\hline A 14 & $\begin{array}{l}\text { Calazans, R., \& Marçal, J. (2011). Os atos do sujeito e a certeza: algumas considerações sobre a } \\
\text { clínica psicanalítica na urgência. Revista Asephallus, 6(12), }\end{array}$ \\
\hline
\end{tabular}


Quanto à procedência dos estudos, em um total de 14 artigos selecionados, 2 foram realizados no estado do Rio Grande do Sul (1 e 2); 5 no estado de Minas Gerais (3, 4, 5, 13 e 14); 3 no estado de São Paulo (artigos 6, 8 e 10); 1 no estado do Rio de Janeiro (11); 1 no estado do Espírito Santo (7); 1 no estado de Alagoas (9); e 1 em Brasília (12). Diante disso, observa-se que a maioria dos estudos se concentraram na região sudeste.

Em relação ao ano dos estudos, 2 foram realizados em 2010 (3 e 5); 1 em 2011 (14); 4 em 2012 (2, 7, 12 e 13); 4 em 2016 (1, 5, 8 e 10); 1 em 2018 (6); e 2 em 2019 (9 e 11). Dessa forma, entende-se que houve mais publicações nos anos de 2012 e 2016. Em relação à formação dos autores, em um total de 33 autores distribuídos em autoria e coautoria nos 14 artigos, infere-se que 31 possuem Graduação em Psicologia, 1 possui Graduação em Ciências Sociais e 1 possui formação em Medicina.

No que diz respeito à formação em psicanálise, 20 possuem formação nessa área. Observa-se que, na busca realizada, foi ausente a autoria de enfermeiros que produzissem sobre o objeto estudado, a mais, evidencia-se que os profissionais que mais produziram sobre o tema foram psicólogos com formação em psicanálise.

Quanto aos objetivos apresentados nos artigos selecionados, destacou-se que 4 artigos, do total de 14 , descreveram a atuação do psicanalista na situação de urgência subjetiva (2, 5, 6 e 13). Quanto aos demais estudos, 3 tiveram como objetivo transmitir a prática de abordagem da urgência subjetiva a partir de teorias baseadas na psicanálise (8, 10 e 11); 1 artigo teve o objetivo de relatar a urgência subjetiva em Instituições Hospitalares (4); seguido de 2 artigos que apresentaram as teorias de Lacan para explicar a urgência subjetiva (7 e 14). Os demais artigos tiveram como objetivo coletar os relatos de experiência profissional de psicólogos de orientação psicanalítica (1); discutir de que maneira a mulher, em situação de emergência obstétrica de alto risco, pode ser afetada pela experiência da urgência subjetiva (9); desenvolver a problemática da urgência na clínica e investigar a população que chega aos serviços de urgência (3); e discutir a definição do trauma para a medicina e para a psicanálise e de que modo essa noção convoca uma discussão sobre a urgência subjetiva(12).

Como já mencionado neste artigo, observa-se que a urgência subjetiva é um tema mais abordado pelo profissional com formação em psicanálise, até mesmo em instituição hospitalar. Quanto aos tipos de estudos, 9 eram Reflexão Teórica $(2,3,5,6,7,10,12,13$ e 14) e os outros 5 foram de Pesquisas Qualitativas. Quanto à abordagem de pesquisa, 2 estudos foram Qualitativos (1 e 9); 1 Abordagem Mista - Qualitativa e Quantitativa (4); 1 Intercessão-Pesquisa (8); e 1 Descritivo e Interpretativo (11).

Quanto aos objetos e recursos técnicos utilizados nos estudos de Reflexão Teórica, 5 artigos envolveram sujeitos no contexto da urgência subjetiva $(1,6,7,10$ e 13); 2 foram com fragmentos de caso (2 e 14); 1 com pacientes da Emergência de um Hospital (3); 1 abordando os pacientes internados no Centro de Terapia Intensiva e seus familiares (5); e 1 com pacientes vítimas de traumas (12).

Nos Estudos Qualitativos, o artigo 9 envolveu a exposição do caso de uma mulher em situação de emergência obstétrica e o 1 pesquisou psicólogos da rede de saúde mental. O estudo Descritivo e Interpretativo (11) se deu com estudantes universitários. Por sua vez, o estudo Qualitativo e Quantitativo (4) investigou 600 prontuários de pacientes e entrevistas com profissionais. $\mathrm{O}$ estudo de Intercessão-Pesquisa (8) envolveu o trabalho e a escuta do sujeito do inconsciente nos termos da urgência subjetiva.

\section{Conceitos de urgência subjetiva encontrados nas produções científicas}

Foi pesquisado nos estudos quais foram os conceitos de urgência subjetiva que os fundamentaram teórico-metodologicamente. O quadro 2, a seguir, se refere aos conceitos apresentados nos estudos.

Quanto às palavras-chave que se articularam para conceituar urgência subjetiva, 6 dos artigos definiram urgência subjetiva relacionando-a à angústia $(1,2,7,8,9$ e 13), 4 referiram-se à trauma $(3,9,10$ e 11), 8 utilizaram-se de sujeitos em momento de crise para explicar a urgência subjetiva $(2,4,5,910,11,13$ e 14), 2 relataram sujeito do sofrimento (6 e 8). Em 2 artigos, a clínica da Urgência foi referida com o sentido de intervenção e não como o de experiência do sujeito (6 e 8).

No que toca à fundamentação teórica dos conceitos dos artigos, esta foi baseada em literaturas ou referenciais teóricos da psicanálise para definir urgência subjetiva. $\mathrm{O}$ estudo (8) utilizou Moura; o estudo (10) utilizou Lacan; os estudos (9 e 12) utilizaram Freud; o estudo (14) utilizou Calazans; o estudo (11) utilizou Stevens; o estudo (3) utilizou Laurent; o estudo (5) utilizou Belaga; o estudo (9) utilizou Ratti \& Estevão e Freud; e o estudo (12) utilizou Laplanche e Pontalis. Alguns estudos utilizaram conceitos próprios como (1, 2, 4, 6, 7 e 13). No que diz respeito aos conceitos apresentados nos estudos selecionados, observa-se que as referências utilizadas foram, na sua maioria, baseadas em literatura. 
Quadro 2 - Conceitos incorporados à revisão integrativa

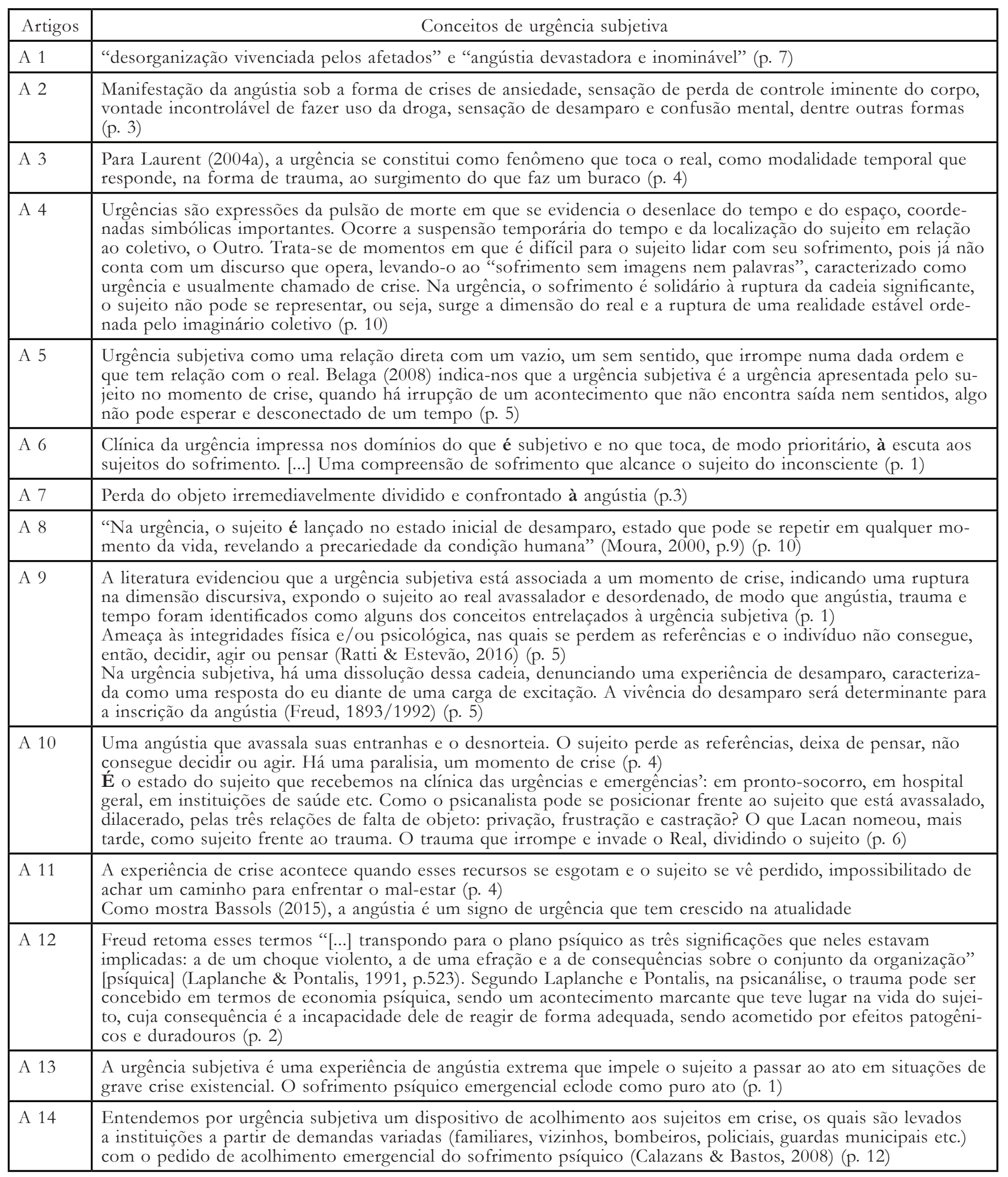




\section{Discussão}

A seguir será apresentada a categoria temática proveniente dos dados que emergiram dos estudos pesquisados.

\section{Experiência do sujeito, reconhecimento e intervenção da urgência subjetiva}

Os dados da pesquisa demonstraram que é ausente a produção de textos que abordassem a noção de urgência subjetiva por enfermeiros independente de formação em psicanálise. Isso pode estar relacionado, por um lado, ao fato de que, mesmo que se tenha enfermeiros analistas ou analistas enfermeiros, ficou ausente a produção nessa pesquisa, por outro lado, a aposta é que pode haver enfermeiros analistas com atuação assistencial no tema da urgência subjetiva. A urgência subjetiva é uma locução clínico-teórica que não é originária do campo das ciências da enfermagem e médica, mas, sim, advinda dos referenciais da psicanálise de Freud e Lacan.

Destarte, essa categoria descreveu a característica da produção científica da urgência subjetiva a partir do que emergiu dos dados e se refere a um processo que contempla como se vivencia e se manifesta a experiência do sujeito quando de uma urgência instalada e como essa experiência é reconhecida e interpelada pelo profissional sob o referencial da psicanálise.

No que se refere à experiência do sujeito ser descrita como uma urgência subjetiva, esta é manifestada por meio de um insuportável, um inadiável, de uma incerteza e instabilidade e que não tem respostas (A9, A11). Assim, a urgência subjetiva compreende uma ruptura aguda da cadeia significante do sujeito cuja pulsão de morte se destaca e há um desenlace do tempo e do espaço, em que o sujeito não consegue simbolizar o que lhe ocorre. Além disso, há uma suspensão em relação ao Outro e com isso falta a palavra, ou seja, "o sujeito não consegue se representar" e "não há tempo" para isso (A2, A4 p. 10, A9, p. 6).

A ideia aplicada por Lacan sobre o significante se atribui ao signo linguístico, considerando que a experiência da psicanálise para o tratamento do sintoma ocorre por meio da linguagem, assim, o significante seria a palavra, e isso diferencia o método psicanalítico do biomédico. O uso que o sujeito faz da linguagem para se colocar na relação com o Outro, como forma de representar a si mesmo (Ferreira, 2002).

Todavia, quando o sujeito se encontra em estado de pulsão de morte, ocorre uma ausência de identidade no processo subjetivo. Secotte et al. (2018, p.253) explicam que "a pulsão de morte estaria a favor da possibilidade da inscrição de um ideal do eu no psiquismo, negando a força das pulsões de vida em conservar a unificação imaginária com o Outro, promovendo uma singularidade, uma possibilidade para "ser diferente".

Para Lacan citado por Quinet (2012), o sujeito se constitui a partir do Outro, o qual, em um primeiro momento, pode ser representado pela mãe do bebê, que representa o Outro do laço social, o pequeno Outro representado pelo espelho do $\mathrm{Eu}$, onde o Eu idealiza no Outro sua própria perspectiva e o grande Outro que, segundo Quinet (2012, p.11), "é de onde vêm as determinações simbólicas da história do sujeito. É o arquivo dos ditos de todos os outros que foram importantes para o sujeito em sua infância e até mesmo antes de ter nascido". Conforme Quinet (2012, p. 9) “o sujeito passará a vida tentando se igualar ao eu ideal, tentando moldar seu eu à imagem e semelhança desse eu ideal que, na função de mãe e função de pai, querem que ele seja, como, por exemplo, 'inteligente', 'bacana', 'bem-sucedido', 'bonito"'.

A urgência também se manifesta por uma dimensão do real que remete a uma relação de vazio como imersão do sujeito na angústia e nesta como resultado que há do encontro do sujeito com o que provoca um sem sentido o qual não pode esperar (A5, A9). De todo modo, foi apontado que, por vezes, "o real da angústia surge a partir do impasse do sujeito diante de seu desejo" e que é necessário escutá-la (A7, p. 11). Porquanto, a manifestação da urgência se dá pela dimensão subjetiva do sofrimento, pois há um sujeito que sofre e se manifesta de maneira singular (A8). A urgência subjetiva também se associa ao que comumente se entende no campo da saúde mental como crise, como algo que se irrompe "e que pode se nomear como trauma" (A9, p. 5).

Segundo Jorge et al. (2005, p.32) "a realidade é constituída por uma trama simbólico-imaginária, feita de palavras e de imagens". Jorge et al. (2005, p.32) ainda afirmam que o real "é precisamente aquilo que não pode ser representado nem por palavras nem por imagens: ao real falta representação psíquica". Segue os autores, "o real é o que está fora do simbólico, sendo por isso mesmo definido como "o impossível de ser simbolizado" (Jorge; Ferreira, 2005, p.35).

Assim, na clínica da urgência, "a avaliação diagnóstica adquire características próprias em função principalmente da temporalidade específica do trabalho do analista 
neste contexto e dos diversos atravessamentos institucionais que se fazem presentes" (A14, p.15), pois, segue o estudo: "na clínica da urgência, lidamos, sobretudo, com os modos de apresentação do sujeito através do ato" (A14, p. 15). Constata-se, assim, que a "contextualização da urgência subjetiva nos interpela com um conjunto de conceitos, como trauma, desamparo, angústia, real e tempo" (A9, p.7).

Em que pese a característica da manifestação da experiência do sujeito nas urgências subjetivas, o estudo A2 sintetiza ao mostrar que

O dispositivo clínico-institucional urgência subjetiva, operado a partir do campo psicanalítico, propõe, a isso que "não cessa de não se escrever", definição de Lacan (1973, p. 556) para o real, alguma forma de inscrição. Pois, na falta de palavras para contornar o real, a angústia irrompe enquanto sinal do real, levando o sujeito à crise psíquica; o que faz com que o recurso tóxico se torne imprescindível ao sujeito frente à confrontação com o vazio que lhe concerne (A2, p. 14).

Desta feita, uma vez instalada uma urgência subjetiva, é conferida ao sujeito a forma como ele lidará com o que lhe ocorre. Ele pode, ou não, de maneira singular, pedir alguma ajuda e essa ser caso a caso. O pedido de intervenção, por vezes, é guiado pela pressa ao restabelecimento de uma suposta normalidade conforme abaixo

Chamou a atenção o caráter premente dos pedidos de ajuda, a angústia e a pressa em se livrar do sofrimento, marcando o modo de chegada assim como a busca por uma forma rápida de restabelecimento da condição anterior ao momento da procura. O manejo da crise subjetiva é desafiador, pois inclui a realização de um diagnóstico situacional, o que, na juventude, inclui estar atento à presença de sinais que podem anteceder a abertura de um quadro mais grave ou o aparecimento de sintomas produtivos que denotam a sua eclosão (A11, p.3).

Todavia, a aproximação entre crise e urgência subjetiva é que a manifestação do sofrimento é a mesma entre esses dois conceitos operadores, mas somente se considera urgência subjetiva a partir do referencial da psicanálise (A8), pois é este quem lhe confere e legítima esse lugar clínico-teórico e interventivo. Dessa forma, como a experiência do sujeito é reconhecida como urgência?
Como é possível afirmar que se trata de uma urgência subjetiva? Por um lado, abre-se um flanco para pensar a saída de uma lógica metafísica de que a urgência deve estar visível como um fenômeno seja no corpo ou como crise. Por outro lado, para que haja esse reconhecimento, é necessário que se dê pela psicanálise e pela presença de analista, não sem a consideração e o manejo da transferência, a qual é imprescindível para todo e qualquer tipo de tratamento em psicanálise. De todo modo, como se reconhece uma urgência subjetiva?

Para se discutir os efeitos dessas práxis, é imprescindível que a clínica da urgência, referenciada pela Psicanálise de Freud e Lacan, passe pela compreensão da urgência subjetiva. É necessário, nesse sentido, superar os conceitos forjados pelo discurso médico, hegemônico no seio hospitalar da Saúde, subvertendo-os. Dessa forma, erguem-se, de modo cauteloso, os pilares da concepção de clínica da urgência; dentre eles, a noção de que há na urgência muito mais do que uma pressa do sujeito por um alívio da dor. Outrossim, para Lacan: "Nada há de criado que não apareça na urgência, e nada na urgência que não gere sua superação na fala" (1966/1998a, p. 242) (A6, p. 3).

A transferência é o ato de repetição de modalidades de experiências de situações anteriores, aplicada a novos relacionamentos, onde se localiza uma resistência ao admitir o novo. Para Freud (1914, p. 170), "a transferência cria uma região intermediária entre a doença e a vida real, através da qual a transição de uma para a outra é efetuada. A nova condição assumiu todas as características da doença, mas representa uma doença artificial, que é, em todos os pontos, acessível à nossa intervenção".

Segue Freud (1914, p.166), ao dizer que "logo percebemos que a transferência é, ela própria, apenas um fragmento da repetição e que a repetição é uma transferência do passado esquecido, não apenas para o médico, mas também para todos os outros aspectos da situação atual)".

É pela transferência que a intervenção à urgência vai sendo construída, na observação de lugares psíquicos trazidos pelo paciente de primeira vez, daquilo que se transfere ao analista a partir da urgência posta e o que se faz com isso. A transferência é um recurso para situar a queixa eminente e a intervenção. Logo, a urgência é um modo singular, caso a caso e que não se trata de mensurar o sofrimento. 
Nessa esteira, o reconhecimento da urgência subjetiva ocorre a partir do referencial da psicanálise, pois a compreensão é que esse conceito se mostra como um operador clínico teórico. A mais, para a clínica psicanalítica, a urgência subjetiva reflete o modo como a intervenção poderá ser realizada. Uma vez reconhecida a urgência, a intervenção perpassa pela singularidade do caso, que envolve a singularidade do sujeito e, portanto, a singularidade da intervenção do profissional.

Os dados das produções aduzem que os sujeitos podem ser levados a instituições por pedidos e pessoas variadas (14), por manifestações da urgência como desamparo, angústia e toxicomanias (A2) e que, por vezes, o sujeito está atravessado mais por perguntas do que pela busca por respostas (A3). Ocorre que, em razão da carência do sentido e do sujeito estar destituído de sua função de enlace ao desejo, o sujeito está tomado pelo que o acometeu, tornando-se objeto da própria dor no confronto com a morte.

Assim, como se afirmou que a urgência se trata de uma ruptura na cadeia significante, um evento traumático que se irrompe e que produz um sem sentido, a intervenção deve suscitar abertura para a inscrição subjetiva, isso para produzir bordas ao real, para que essa escuta possibilite aproximação entre sujeito e profissional para se constituir a possibilidade de uma transferência (A2, A3, A4).

A urgência psíquica ocorre quando um sujeito atinge o limite e requer a resolução de algo aqui e agora. Sob demanda para uma solução imediata, o analista praticante responde, como Ricardo Seldes aponta (2008), introduzindo uma pausa na urgência e abrindo outra porta, a porta da subjetividade. A abertura deste pode levar a transição da urgência generalizada para a urgência subjetiva, que não é produzida sem um analista (A3, p. 3).

A inscrição subjetiva se trata de trazer o sujeito para o local onde ele pode conferir a sua experiência subjetiva, um espaço de fala que possa buscar sentido ao insuportável, assim, as bordas ao real consistem do limite ao simbólico, imaginário, um limite ao que o sujeito está imaginando, para que possa retornar ao seu "consciente", onde poderá marcar sua subjetividade e encontrar a cadeia de significante a qual foi corrompida na urgência subjetiva, ou seja, trata-se de uma reconstrução, um novo olhar sobre o sujeito.
A intervenção na urgência consiste em um encontro para que algo se inicie, pois o analista deve se ocupar das diversas formas de manifestação do sujeito e, com isso, o sujeito pode ser escutado (A5). Isso porque, diferente de outros referenciais teóricos que buscam privar o sujeito da fala com recursos químicos como primeira opção como padrão, na urgência subjetiva, a fala do sujeito é a oportunidade para a subjetivação da experiência do sofrimento (A9). Um encontro permeado de acolhimento (A4) e que envolve uma avaliação de risco, no qual pode haver uma discussão de caso com membros de equipe (A11).

Uma vez iniciado o encontro, a urgência subjetiva perpassa por três momentos:

O primeiro, marcado pela urgência generalizada, é a precipitação do sujeito à instituição hospitalar. Não há, em tal estágio, transferência endereçada ao saber encarnado no psicólogo precavido pela psicanálise. No segundo, concernente à recepção do sujeito, tem início o processo de transferência, no qual o sujeito começa a supor um saber no dispositivo analítico. E, no terceiro, há o estágio de encaminhamento do sujeito para uma "direção de tratamento" noutro lugar, com outro profissional referenciado na Psicanálise (A6, p.4).

O estudo A (14) refere que a passagem de um momento a outro é singular ao sujeito, ao profissional, à instituição e à equipe, pois, a cada caso, se trata de uma nova busca por resolução, um novo encontro (A3).

Deve-se acrescentar que, no momento da ruptura e crise, a urgência não é subjetiva, mas generalizada. De modo a designar como urgência subjetiva, é necessário, conforme proposto por Inés Sotelo (2009), que se localize o assunto da urgência e aposte na palavra como gesto mínimo, elementar: aqui está o primeiro nível de tratamento de urgência (A3, p.3).

A localização do que se trata a urgência é feita pela escuta, pois é pela escuta que a transferência poderá ser estabelecida, norteada por uma ética. Uma escuta precavida pela psicanálise (A6), que busque ressignificar a vivência da angústia e reorganize o insuportável (A1). A escuta deve permitir ao sujeito se questionar sobre suas palavras (A3, p. 5), favorecer o saber-fazer do sujeito (A 10) para que este produza sentido na experiência traumática (A1). A escuta fornece aos sujeitos a possibilidade de 
"invenções, abrindo tempo e espaço" (A5, p.8) para que, a partir de seu trauma-processo e das diversas possibilidades de inscrições ou respostas, ele possa se estabelecer (A, p. 12). A ética da psicanálise significa que o analista possui um lugar e deve suportar o horror da castração e operar em ato, para que o sujeito faça laço social. Assim, o analista deve estar advertido de seu próprio narcisismo principalmente em situações limite (A10, p.13).

No que se refere à transferência, o profissional possui uma dimensão de responsabilidade concernente "ao seu lugar que ocupa frente aos atos", um lugar de Outro (A13, p. 15) baseado na ética.

Sendo assim, podemos sinalizar a importância de que a continuidade desse trabalho depende consideravelmente de que o trabalhador, nessa práxis, tenha uma formação que caminhe numa linha orientada por uma Ética, enquanto Ética da singularidade, do sujeito do inconsciente e do bem-dizer (Lacan, 1986/1997). Somente com essa implicação, aliada à abertura da equipe de trabalhadores para a dimensão subjetiva, e com a efetividade de uma participação do psicólogo neste contexto, poderemos pensar e avançar na regulamentação e implantação da prática de uma Psicologia num espaço institucional como um PS (A8, p. 13).

A escuta remete à fala, a qual "é a ponte para a superação da angústia e dos impasses relatados pelos sujeitos em suas demandas, poder saber do seu próprio saber: 'O que sou?' Sou somente isso, uma doença, pela qual estou me representando?” (A6, p. 3). Para que as produções do desejo possam emergir por meio do tratamento pela palavra (A6), e o sujeito tenha a possibilidade de se interrogar pelo que provocou o rompimento da cadeia significante e produziu a urgência e encontrar sua maneira singular de lidar com o insuportável, esse real que irrompe, ou seja, a possibilidade de simbolizar o que está fragmentado, a necessário da fala, uma produção de significante pela pontuação (A9).

A cadeia significante é o que se refere à própria cadeia da linguagem, em que um significante requer outros significantes para obter um significado (um sentido). Segundo Salztrager (2008, p.56), “o significante não remete diretamente a nenhum significado; mas se articula com outros significantes na forma de uma cadeia para produzir o fenômeno da significação". Para Ferreira-Lemos (2011, p.103) "a trama do significante se dá neste encontro do sujeito com o Outro, assim como é desse encontro que sujeito e Outro passam a existir desse modo".

"Há aqui um significante primordial, que chamamos de S1, e que será condicional para a estrutura da cadeia significante do sujeito" (Ferreira-Lemos, 2011, p.103)

No encontro do sujeito com algo insuportável de ser colocado em palavras, coube à analista retomar o convite para a fala e apostar no endereçamento desse ato como forma de se alcançar o tempo de compreender e propiciar o desenrolar do tratamento psicanalítico (A13, p.7). Na urgência, a intervenção requer um tempo de pausa para que o sujeito possa fazer laço social (A1, A14). Assim, da intervenção, surgem os efeitos na urgência subjetiva

Os relatos iam se modificando no espaço de escuta, e a apreensão da vivência traumática pelo psiquismo foi possibilitando a retomada das atividades da vida diária, como frequentar a faculdade e ir a eventos sociais. Como resultado, houve a diminuição ou eliminação do medo do escuro e dos sintomas psicóticos, melhorando a qualidade do sono, resgatando os vínculos pessoais, assim como o desejo de investir em novos projetos de vida (A1, p. 8).

Entende-se que um dos efeitos gerados pela intervenção é a implicação do sujeito em dar seguimento ao tratamento e, com isso, o profissional, além da clínica psicanalítica, deve ter conhecimento do trabalho em Rede para que o encaminhamento seja o mais coerente possível a partir do que foi escutado, preservando a singularidade de cada localização institucional (A6).

A Urgência subjetiva é um tema essencialmente estudado no campo da psicanálise, porém é uma questão de saúde mental, considerando os sintomas psíquicos que o sujeito apresenta, visto a necessidade de refletir a urgência subjetiva no escopo multiprofissional. Isso diz de um preparo do profissional de saúde disponível tanto para o conhecimento quanto para a prática no serviço, para que possa realizar o acolhimento a esse sujeito que se encontra em desespero. Esse preparo considera a necessidade de esse profissional pensar a sua urgência, o estudo teórico, sua análise pessoal e a sua supervisão do caso para legitimar a intervenção no campo da urgência subjetiva como dispositivo clínico da psicanálise. Um preparo que leve em consideração o caminho da escuta psicanalítica em sintonia com os determinantes sociais da saúde coletiva. 


\section{Conclusão}

A descrição das características das produções científicas relativas à urgência subjetiva indicou que há um quantitativo significativo de produções, bem como que há variedade de conceitos fundamentados por Freud e Lacan. Os estudos, em sua maioria, revelaram que os conceitos apresentados nos estudos estão atrelados a palavras como angústia, trauma, sujeitos em momento de crise, sofrimento do sujeito e clínica da urgência, sendo, portanto, relativos à intervenção e não à experiência do sujeito. O tema urgência subjetiva é abordado essencialmente pelo profissional psicanalista mesmo em instituições hospitalares. Além disso, tendo em vista a analogia nos sentidos de urgência subjetiva e crise, a urgência subjetiva só pode ser assim denominada por meio do referencial da psicanálise, a mais, sua abordagem consiste em uma escuta analítica, baseada na singularidade do sujeito e do profissional, visto que a intervenção preferencial, nos atendimentos aos sujeitos em crise, geralmente, acontece por meio dos recursos químicos, impossibilitando a fala do sujeito. Destaca-se, assim, que, na urgência subjetiva, a intervenção ocorre pelo espaço dado ao sujeito para expor o seu sofrimento.

A identificação das produções científicas as quais relacionam urgência subjetiva, psicanálise e enfermagem revelou uma ausência de produções em urgência subjetiva na enfermagem, mas, por outro lado, percebeu-se um destaque para produções em urgência subjetiva realizadas por autores os quais, na sua maioria, são profissionais da psicologia com formação em psicanálise. A partir deste estudo, foi possível compreender que a urgência subjetiva é um dispositivo clínico pensado pela psicanálise como campo de atuação, a qual se manifesta no sujeito de maneira singular e produz sofrimento, desamparo e angústia. Nesse momento, o sujeito encontra dificuldade para nominar o que o atravessa, o que ocasiona um conflito entre a realidade psíquica e a realidade factual.

Conclui-se que é possível a enfermagem se utilizar de artifícios teóricos e clínicos do dispositivo da clínica da urgência subjetiva para ampliar o escopo de sua intervenção para uma escuta analítica, pois essa profissão acompanha e assiste o paciente 24 horas. Ainda, novos estudos poderão se constituir a partir da urgência subjetiva no que se refere às estruturas clínicas da neurose, psicose e perversão, e sobre quais seriam as especificidades que eclodem em cada uma delas e na escuta profissional.

\section{Referências}

Barros, R. R. (2008). A urgência subjetiva: Urgência sem emergência? Rio de Janeiro: Subversos, 49-69.

Calazans, R., \& Bastos, A (2008). Urgência subjetiva e clínica psicanalítica. Revista Latinoamericana de Psicopatologia Fundamental. 11(4),640-652.

Costa, M. F. (2019). Urgência e sujeito numa unidade hospitalar: ensaios sobre a práxis da psicanálise na instituição de saúde. Londrina: Eduel.

Ferreira, N. P. Jacques Lacan: apropriação e subversão da lingüística. Ágora: Estudos em Teoria Psicanalítica, [S.L.], v. 5, n. 1, p. 113-131, jun. 2002. FapUNIFESP (SciELO). http://dx.doi.org/10.1590/s1516-14982002000100009.

Ferreira-Lemos, P. P. (2011). Sujeito na psicanálise: o ato de resposta à ordem social. In: M. J. P. Spink, P. Figueiredo, \& J. Brasilino (Eds.), Psicologia social e pessoalidade. Rio de Janeiro: Centro Edelstein de Pesquisas Sociais; ABRAPSO, 89-108.

Freud, S. (1996) Recordar, Repetir E Elaborar. In Freud, S. [Autor], Edição standard brasileira das obras psicológicas completas de Sigmund Freud, v. XII. Rio de Janeiro: Imago. (Original publicado em 1914).

Freud, S. (1996). Dois verbetes de enciclopédia. In S. Freud (Ed.) Edição standard brasileira das obras psicológicas completas de Sigmund Freud, v. XVIII. Rio de Janeiro: Imago.

Ganong, L. H. (1987). Integrative reviews of nursing. Revista Nurs Health, 10(1), 1-11.

Jorge, M. A. C; Ferreira, N. P. Lacan, o grande freudiano. Rio de Janeiro: Zahar, 2005.

Kaszubowski, E. (2018). O conceito de sujeito nos antecedentes lacanianos: uma leitura em nachträglichkeit. Ágora: estudos em Teoria Psicanalitica, 21(1), 105-115. http://dx.doi.org/10.1590/1809-44142018001010.

Minayo, M. C. S. (2014). O desafio do conhecimento: pesquisa qualitativa em saúde. 14nd ed. São Paulo; Hucitec.

Quinet, A. (2012). Os outros em Lacan. Rio de Janeiro, Zahar.

Salztrager, R. Das fantasias vazias ao referencial discursivo. Ágora, Rio de Janeiro, v. 11, n. 1, p. 53-65, jun. 2008.

Sbardelotto, L., Ferreira, D., Peres, M. I. L., \& Oliveira, A. M. M. (2016). A Constituição do sujeito na psicanálise. Akrópolis, 24(2), 113-129.

Secotte, G., \& Dionisio, G. H. (2018). Pulsão de morte e agressividade no campo de Freud-Lacan. Analytica: Revista de Psicanálise, 7(13), 238-258.

Sotelo, I. (2020). DATUS: dispositivo analitico para el tratamiento de urgencias subjetivas. Buenos Aires: Grama Ediciones.

Submetido em: 4-6-2021

Aceito em: 17-11-2021 